\title{
Synthesis of 1-trimethylsilyl-2-arylcyclohexenes: a new class of anionic synthons
}

\author{
A. S. Jeevan Chakravarthy, M. S. Krishnamurthy, Noor Shahina Begum, S. HariPrasad* \\ Department of Post Graduate Studies in Chemistry, Central College Campus, Bangalore University, Palace Road, Bangalore 560 001, India
}

\section{A R T I C L E I N F O}

\section{Article history:}

Received 23 May 2016

Revised 9 June 2016

Accepted 12 June 2016

Available online 14 June 2016

\section{Keywords:}

Cyclic vinylsilanes

Anionic synthons

Halogenated cyclohexenes

Single crystal XRD

Atropisomerism

\begin{abstract}
A B S T R A C T
The sequential synthesis of eleven novel 1-trimethysilyl-2-arylcyclohexenes $\mathbf{4 a - k}$ from 1-bromo-2chlorocyclohexene $(\mathbf{1})$ is reported. The Suzuki cross coupling of $\mathbf{1}$ with eleven aryl boronic acids $\mathbf{2 a - k}$ gave the 1-chloro-2-arylcyclohexenes $\mathbf{3 a}-\mathbf{k}$ in $>90 \%$ yields. Wurtz-Fittig coupling reaction of $\mathbf{3 a - k}$ with metallic sodium and chlorotrimethylsilane in anhydrous ether solvent afforded the novel anionic synthons: 1-trimethylsilyl-2-arylcyclohexenes $\mathbf{4 a - k}$ in $65-87 \%$ yields. The cyclic vinylsilanes $\mathbf{4 a - j}$ are liquids, and 1-trimethylsilyl-2-biphenylcyclohexene (4k) exists as a solid. The crystal structure of $\mathbf{4 k}$ is discussed. A plausible mechanism for the Wurtz-Fittig reaction and formation of vinylsilanes is highlighted.
\end{abstract}

(C) 2016 Elsevier Ltd. All rights reserved.

\section{Introduction}

Sequential transformations of organometallic reagents have been used in the last 30 years for the synthesis of highly functionalized olefins, which find immense applications in organic synthesis and materials science. ${ }^{1}$ In this regard, the synthesis of simple and substituted vinylsilanes/vinylstannanes has attracted a high amount of attention from scientists worldwide. ${ }^{2,3}$ The compounds are anionic synthons. In recent years several methods have been developed for the preparation of vinylsilanes. ${ }^{4,5}$ The compounds undergo regio- and stereo-specific transformations, ${ }^{6}$ and have been especially used as starting compounds in the total synthesis of natural products, ${ }^{7}$ Hiyama cross-coupling reactions, ${ }^{8}$ and Hosomi-Sakurai-type allylation/crotylation reactions. ${ }^{9}$

Our laboratory deals with the synthesis and study of the reactions of some simple ${ }^{10 a}$ and substituted cyclic vinylsilanes which have included: 1-halo-2-trimethylsilylcycloalkenes, ${ }^{10 \mathrm{~b}}$ allyl- $N$ amino substituted cyclic vinylsilanes, ${ }^{10 c} \alpha$-trimethysilyl- $\alpha, \beta-$ unsaturated cycloalkenones, and 2-(hydroxydimethylsilyl)cycloalk-2-enones, ${ }^{10 \mathrm{~d}}$ 6-trimethylsilylspiro[4,n]alk-6-enes, ${ }^{10 \mathrm{e}}$ 1,2bis(trimethylsilyl)-cycloalkenes, ${ }^{10 \mathrm{~b}, \mathrm{~g}}$ 1,3-bis(trimethylsilyl)cycloalkenes, $^{1 \text { of }} \quad$ 1,3,3-trimethyl-2-(trimethylsilyl)cycloalkenes, ${ }^{7 \mathrm{~d}}$ and (spirocycloalkenyl)trimethylsilyl-acetylenes. ${ }^{10 \mathrm{~h}}$ The compounds serve as anionic synthons which undergo regio- and stereospecific transformations.

\footnotetext{
* Corresponding author. Tel.: +91 8022961351.

E-mail address: hariprasad@bub.ernet.in (S. HariPrasad).
}

In further continuation of our studies, we now report for the first instance of time, starting from 1-bromo-2-chlorocyclohexene (1), the synthesis of eleven novel 1-aryl-2-trimethysilylcyclohexenes $\mathbf{4 a - k}$, by employing sequential transformation methodology. Till date, all the cyclic vinylsilanes prepared in our laboratory have existed as liquids. As a first instance, we now report the isolation of a cyclic vinylsilane 1-trimethylsilyl-2-biphenylcyclohexene (4k), which exists as a solid. The single crystal XRD of $\mathbf{4 k}$ is reported.

\section{Results and discussion}

Aryl substituted cyclohexenes form an important class of compounds in synthetic organic chemistry. Differently substituted aryl cyclohexenes find a wide range of applicability in organic synthesis and natural products chemistry. ${ }^{11 a-h}$ Our interest in the synthesis of novel anionic synthons prompted us explore the possibility of converting 1-bromo-2-chlorocyclohexene (1) to some novel aryl substituted cyclic vinyl silanes which would serve as anionic synthons. $^{12}$

With this aim, the Suzuki cross-coupling reaction of 1-bromo-2chlorocyclohexene (1) with eleven boronic acids $\mathbf{2 a - k}$ using 1,4dioxane solvent and $\mathrm{Pd}(\mathrm{dppf})_{2} \mathrm{Cl}_{2}$ catalyst in a sealed tube at $110^{\circ} \mathrm{C}$ was carried out. The reactions gave the 1-chloro-2-aryl cyclohexenes 3a-k in $87-90 \%$ yields. ${ }^{12}$ Similar Heck reaction ${ }^{13}$ of 1 -chlorocyclohexene with aryl bromides in cat. $\mathrm{Pd}(\mathrm{OAc})_{2} / \mathrm{DMSO}$ solvent/NaOAc/2-dicyclohexylphosphino-2', $4^{\prime}, 6^{\prime}$-triisopropylbiphenyl gave $3 \mathbf{a}-\mathbf{k}$ in $36-54 \%$ isolated yields. 


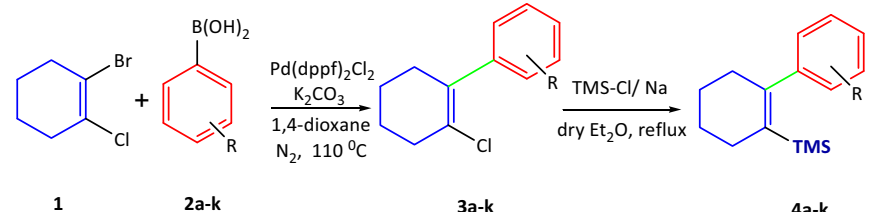

Figure 1. Sequential transformation for the synthesis of 1-trimethylsilyl-2-aryl cyclohexenes.

The next sequential Wurtz-Fittig cross-coupling reaction of 3a-k with sodium and chlorotrimethylsilane in anhydrous ether solvent gave the novel cyclic vinylsilanes $\mathbf{4 a - k}$. The methodology is given in Figure 1.
The spectral characterization of the compounds has been completed and summarized in experimental. The optimized yields of the products $\mathbf{3 a - k}$ and $\mathbf{4 a - k}$ are given in Table 1. Compounds $\mathbf{4 a}-\mathbf{j}$ exist as liquids and $\mathbf{4 k}$ was isolated as a clear colorless solid.

Petrov for the first time synthesized the cyclic vinylsilane: 1-trimethylsilylcyclohexene from 1-chlorocyclohexene, by using Wurtz-Fittig coupling reaction as a clear colorless liquid. ${ }^{14}$ Further studies in our laboratory, over the years, have always yielded a large number of cyclic vinylsilanes as liquids. ${ }^{10 \mathrm{a}-\mathrm{h}}$ Now, for the first time, we found that the compound 1-trimethylsilyl-2-biphenylcyclohexene (4k) exists as a solid.

The structure of the molecule is shown in Figure 2. The orientation of the biphenyl group with respect to the cyclohexene moiety is depicted in Figure 3. The molecule exhibits atropisomerism.

Table 1

1-Trimethylsilyl-2-arylcyclohexenes via Wurtz-Fittig coupling

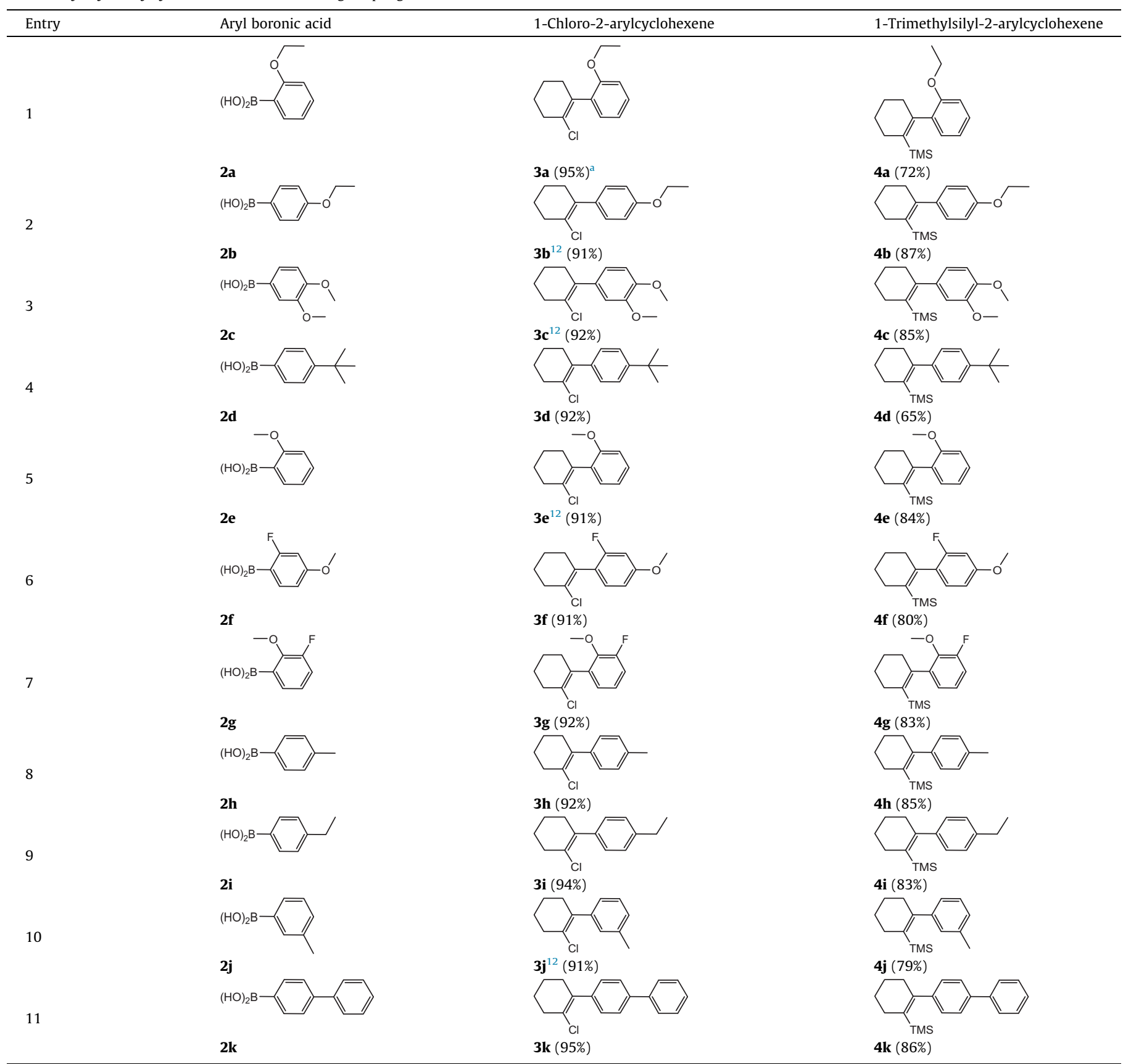

\footnotetext{
${ }^{a}$ Numbers in the parenthesis indicate the isolated yields.
} 


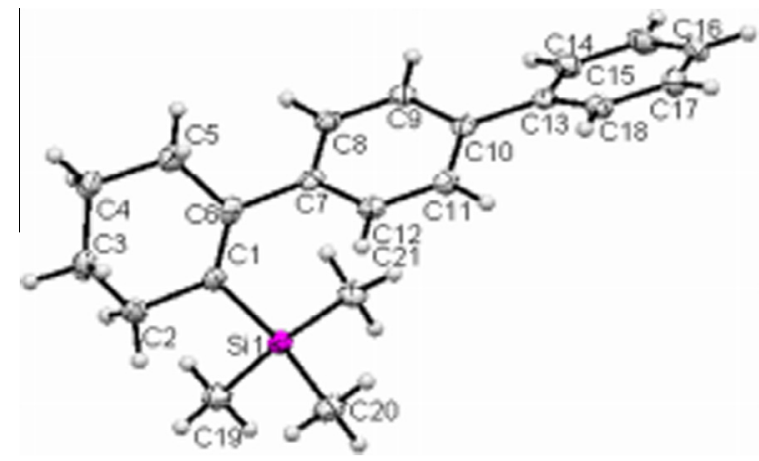

Figure 2. ORTEP view of compound $\mathbf{4 k}$, showing $50 \%$ probability ellipsoids and the atom numbering scheme.

Compound $\mathbf{4 k}$ crystallizes in the orthorhombic crystal system with space group Pbca containing one molecule in the asymmetric unit. The trimethylsilyl (TMS) substituted phenyl ring at carbon C6 is positioned axially bisecting the biphenyl ring with a dihedral angle of $73.53(4)^{\circ}$ (Fig. 3). The two phenyl rings of the biphenyl moiety are non-coplanar (dihedral angle $=25.148^{\circ}$ ). TMS substituted phenyl ring is significantly puckered and adopts twist-boat conformation with atoms C1 and C4 displaced by -0.0219 (3) $\AA$ and 0.6512 (6) $\AA$ from the mean plane of the other four atoms (C2/C3/C5/C6), respectively. ${ }^{15}$ This may be due to the presence of a bulky TMS group attached to the cyclohexenyl ring.

\section{Mechanism}

The mechanism for the formation of the products $3 \mathbf{a}-\mathbf{k}$ is expected to traverse through the pathways well established for the Suzuki process.

However, in the case of the Wurtz-Fittig coupling reactions for formation of $\mathbf{4 a - k}$, we have always observed that there would be the formation of a deep navy-blue coloration, under the near perfect anhydrous conditions employed during the reactions, which indicated the formation of the cyclic vinylsilanes in-situ. No reasonable mechanism has been given till date, for the formation of the deep-blue coloration since Petrov's first synthesis of 1-trimethylsilylcyclohexene. ${ }^{14}$ It may be noted here that vinyl metal species prepared in other ways, tend not to be deep blue. In this context, we now postulate that since the reactions are normally carried out in ethereal solvents, the sodium metal transfers an electron to the carbon-halogen bond, resulting in the formation of the vinylic anion and sodium counter-ion. ${ }^{10 \mathrm{~b}, 16 \mathrm{a}}$ The $\mathrm{Na}^{+}$ions being solvated, is then surrounded by four ether molecules to form a loosely bound complex. ${ }^{16 b, c}$ Further, due to the excess sodium metal present, there may exist a sea of electrons similar to sodium/liquid ammonia which ultimately lead to the formation of the deep navy-blue coloration of the reaction mixture. ${ }^{16 \mathrm{~d}}$ Subsequent SN2 attack of the vinylic anion on TMS-Cl yields the cyclic vinylsilanes.

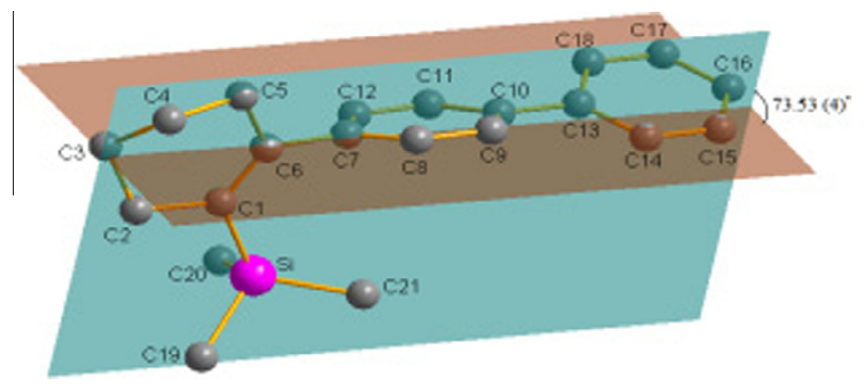

Figure 3. The intersection of the two planes containing the TMS substituted aryl ring and biphenyl ring.

\section{Conclusions}

The synthesis of 1-chloro-2-arylcyclohexenes and 1-trimethysilyl-2-arylcyclohexenes by a combination of Suzuki coupling and Wurtz-Fittig reaction is reported. The route is characterized by the easy preparation of starting materials, from inexpensive chemicals and easy isolation methods.

\section{General procedure for preparation of:}

\section{1-Chloro-2-aryl-cyclohexenes (3a-k)}

To $250 \mathrm{mg}$ (1.2755 mmol) of 1-bromo-2-chlorocyclohexene (1) taken in a pressure tube was added aryl boronic acid (2a-k) (1.40 mol equiv), $\mathrm{Pd}(\mathrm{dppf})_{2} \mathrm{Cl}_{2} \quad(0.6 \mathrm{~mol} \%)$ catalyst, $\mathrm{K}_{2} \mathrm{CO}_{3}$ (3.82 mol equiv), and anhydrous 1,4 -dioxane $(2.5 \mathrm{~mL})$. The pressure tube was purged with anhydrous nitrogen gas and then capped. The pressure tube was introduced to a preheated oil bath at $110^{\circ} \mathrm{C}$ and the reaction mixture was heated for $4 \mathrm{~h}$ under magnetic stirring. The reaction mixture was cooled, diluted with $30 \mathrm{~mL}$ ethyl acetate, and filtered through a Celite bed. The excess solvent was removed on a rotary evaporator and crude residue purified by column chromatography using silica gel (100-200 mesh) and 1:5 ethyl acetate-petroleum benzine $\left(60-74{ }^{\circ} \mathrm{C}\right.$ fraction). The pure compounds 3a-k which appeared as single spot on TLC under UV lamp, were isolated and spectrally characterized. The yields are given in Table 1 . The compounds $\mathbf{3 a} \mathbf{a}-\mathbf{k}$ were then used for the next step.

\section{1-Trimethylsilyl-2-arylcyclohexenes (4a-k)}

The 1-chloro-2-arylcyclohexenes $\mathbf{3 a - k}$ prepared as given above, $(1.0 \mathrm{mmol})$, were dissolved individually in $3 \mathrm{~mL}$ ether.

To a suspension of finely cut sodium metal ( $3 \mathrm{~g}$ atom equiv) and chlorotrimethylsilane ( $4 \mathrm{~mol}$ equiv) in $3 \mathrm{~mL}$ dry ether was added the ethereal solution of the individual chloro-compound 3a-k. The mixture was heated at reflux temperature employing a Graham water cooled condenser with $\mathrm{CaCl}_{2}$ guard tube. The reflux was continued till the appearance of deep navy-blue coloration, and then the reactions were monitored by TLC and GC through micro work-up of aliquots. After completion of the reaction as indicated by the chromatograms, the reaction mixture was cooled to ambient temperature, the precipitated solid and remaining sodium were removed by filtering on a plug of glass wool and washed with ether $(2 \times 5 \mathrm{~mL})$. The combined organic extract was washed with saturated sodium bicarbonate $(15 \mathrm{~mL})$, saturated brine $(15 \mathrm{~mL})$, water $(3 \times 10 \mathrm{~mL})$, and dried over anhydrous $\mathrm{K}_{2} \mathrm{CO}_{3}$. The combined extract was concentrated on a rotary evaporator and purified by column chromatography, using silica gel (230-400 mesh) and $n$-hexane $\left(60-74^{\circ} \mathrm{C}\right.$ fraction) as mobile phase, to obtain the pure compounds $\mathbf{4 a - k}$.

\section{Acknowledgments}

The authors thank (1) Bangalore University; (2) University Grants Commission (KMS for a UGC-BSR meritorious fellowship); and (3) Department of Science and Technology, Government of India - New Delhi. Grateful thanks are placed on record to the Indian Institute of Science, Bangalore for the spectral analysis.

\section{Supplementary data}

Supplementary data associated with this article can be found, in the online version, at http://dx.doi.org/10.1016/j.tetlet.2016.06. 051. 


\section{References and notes}

1. Szudkowsja-Fractzak, J.; Hrechzycho, G.; Pawluc, P. Org. Chem. Front. 2015, 2 730-738.

2. Lim, D. S. W.; Anderson, E. A. Synthesis 2012, 44, 983-1010.

3. Shipe, W. D.; Sorenson, E. J. J. Am. Chem. Soc. 2006, 128, 7025.

4. (a) Oshima, K. In Fleming, I., Ed.; Science of Synthesis; Thieme: Stuttgart, 2001; Vol. 4, pp 713-754; (b) Sarkar, T. K. In Fleming, I., Ed.; Science of Synthesis; Thieme: Stuttgart, 2001; Vol. 4, pp 837-924.

5. For recent advances in the preparation of allyl and vinyl silanes see: (a) Trost, B. M.; Ball, Z. T. J. Am. Chem. Soc. 2005, 127, 17644-17655; (b) Ohmiya, H.; Yorimitsu, H.; Oshima, K. Org. Lett. 2006, 8, 3093-3096; (c) Hayashi, S.; Hirano, K.; Yorimitsu, H.; Oshima, K. J. Am. Chem. Soc. 2007, 129, 12650-12651; (d) Berthon-Gelloz, G.; Schumers, J’. M.; Bo, G. D.; Mark, I. E. J. Org. Chem. 2008, 73, 4190-4197; (e) Nakamura, S.; Yonehara, M.; Uchiyama, M. Chem. Eur. J. 2008, 14, 1068-1078; (f) Murakami, K.; Yorimitsu, H.; Oshima, K. J. Org. Chem. 2009, 74, 1415-1417; (g) Rooke, D. A.; Ferreira, E. M. J. Am. Chem. Soc. 2010, 132, 11926-11928; (h) Lim, D. S. W.; Anderson, E. A. Org. Lett. 2011, 13, 4806-4809.

6. (a) Curtis-Long, M. J.; Aye, Y. Chem. Eur. J. 2009, 15, 5402; (b) Brook, M. A. Silicon in Organic, Organometallic, and Polymer Chemistry; Wiley: Chichester, 2000; (c) Fleming, I.; Dunogues, J.; Smithers, R. In Organic Reactions; Wiley: New York, 2004; pp 57-575.

7. (a) Langkopf, E.; Schinzer, D. Chem. Rev. 1995, 95, 1375-1408; (b) Vadala, A.; Finzi, P. V.; Zanoni, G.; Vidari, G. Eur. J. Org. Chem. 2003, 4, 642-648; (c) Ishihara, Y.; Mendoza, A.; Baran, P. S. Tetrahedron 2013, 69, 5685-5701; (d) Venkatesha, M. A.; HariPrasad, S. J. Serb. Chem. 2013, 78, 759-768.

8. (a) Nakao, Y.; Hiyama, T. Chem. Soc. Rev. 2011, 40, 4893-4901; (b) Denmark, S. E.; Liu, J. H.-C. Angew. Chem. 2010, 122, 3040-3049; Denmark, S. E.; Liu, J. H.-C. Angew. Chem. 2010, 49, 2978-2986.

9. (a) Hosomi, E. M.; Sakurai, H. Chem. Lett. 1976, 941-942; (b) Masse, C. E.; Panek, J. S. Chem. Rev. 1995, 95, 1293-1316; (c) Denmark, S. E.; Fu, J. Chem. Rev. 2003, 103, 2763-2793.
10. (a) Nagendrappa, G. Synthesis 1980, 704-706; (b) HariPrasad, S.; Nagendrappa, G. Tetrahedron 1993, 3387-3396; (c) HariPrasad, S.; Nagendrappa, G. Indian J. Chem. 1997, 36B, 1016-1019; (d) Jyothi, D.; HariPrasad, S. Arkivoc 2012, vi, 194-203; (e) Venkatesha, M. A.; HariPrasad, S. Bulgarian Chem. Commun. 2012, 44, 155-158; (f) Venkatesha, G. B.; HariPrasad, S. Lett. Org. Chem. 2012, 9, 696700; (g) HariPrasad, S.; Nagendrappa, G. J. Ind. Chem. Soc. 2012, 89, 287-289; (h) Venkatesha, M. A.; HariPrasad, S. Lett. Org. Chem. 2013, 10, 457-461.

11. (a) Turk, C. F.; Krapcho, J. US. Patent 4118558 A, 1978, Squibb and sons.; (b) Caprathe, B. W.; Jaen, J. C.; Smith, S. J.; Wise, L. D. U.S. Patent 4975445 A, 1990 Warner-Lambert.; (c) Welker, M. E. Tetrahedron 2008, 64, 11529-11539; (d) Das, M. K.; De, S.; Bisai, S. A. Org. Biomol. Chem. 2015, 13, 3585; (e) Kakde, B. N.; Bhunia, S.; Bisai, A. Tetrahedron Lett. 2013, 54, 1436-1439; (f) Beard, R. L.; Klein, E. S.; Standeven, A. M.; Escobar, M.; Chandraratna, R. S. Bioorg. Med. Chem. Lett. 2001, 11, 765-768; (g) Yakaiah, T.; Kurumurthy, C.; Lingaiah, B. P. V.; Narsaiah, B.; Pamanji, R.; Velatooru, L. R.; Rao, V. J.; Gururaj, S.; Parthasarathy, T.; Sridhar, B. Med. Chem. Res. 2012, 21, 4261-4273; (h) Koerwitz, F. L.; Hammond, G. B.; Wiemer, D. F. J. Org. Chem. 1989, 54, 743.

12. Lokesh, K.; HariPrasad, S. Org. Chem. Int. 2014. http://dx.doi.org/10.1155/2014/ 871595.

13. Hartung, C. G.; Kohler, K.; Beller, M. Org. Lett. 1999, 1, 709-711.

14. Petrov, A. D.; Plate, A. F.; Cheryshev, E. A.; Dolgaya, M. E. Zh. Obshch. Khim. $1961,4,1199$.

15. Cremer, D.; Pople, J. A. J. Am. Chem. Soc. 1975, 97, 1354

16. (a) Walborsky, H. N.; Hanbouchi, C. J. Am. Chem. Soc. 1993, 115, 6406; (b) Day M. C. Pure Appl. Chem. 1977, 49, 75-81; (c) Ziegler, M. J.; Madura, J. D. J. Solution Chem. 2011, 40, 1383-1398; d) We are thankful to Dr. Cox, L. R., School of Chemistry, Birmingham University, Birmingham, UK, for the insight.

17. Bruker SMART, SAINT-Plus, SADABS; Bruker AXS: Madison, 1998.

18. Sheldrick, G. M. Acta Crystallogr., Sect. A 2008, 64, 112.

19. Farrugia, L. J. J. Appl. Crystallogr. 1997, 30, 565.

20. Nardelli, M. Acta Cryst. 1983, C39, 1141. 